\title{
Malignant melanoma in families of children with osteosarcoma, chondrosarcoma, and adrenal cortical carcinoma
}

\author{
ANN L HARTLEY*, JILLIAN M BIRCH*, HENRY B MARSDEN*, \\ AND MARTIN HARRIS † \\ From *the Department of Epidemiology and Social Oncology, Children's Tumour Registry, and $\dot{\dagger}$ the \\ Department of Pathology, Christie Hospital and Holt Radium Institute, Manchester M2O 9BX.
}

SUMMARY Seven cases of malignant melanoma in the close relatives of children with osteosarcoma and chondrosarcoma are described. The association between certain childhoot malignancies (adrenal cortical carcinoma, osteosarcoma, chondrosarcoma, retinoblastoma) anc\$ malignant melanoma is discussed and it is proposed that in certain families malignant melanomio may be another manifestation of the same gene defect which results in susceptibility to tumours characteristic of the SBLA cancer family syndrome.

Malignant melanoma constitutes about $1 \%$ of all malignancies and most cases are thought to be sporadic. Certain heritable forms of melanoma have, however, been described. Inherited site specific cutaneous melanoma in a father and two of his children was first reported by Cawley ${ }^{1}$ and attention was drawn to the occurrence of melanoma with other malignancies by Lynch et $a l^{2}{ }^{2}$ who described three families where malignant melanoma appeared to be associated with carcinoma of the breast and gastrointestinal tract. Malignant melanoma of the choroid has also been observed in association with neurofibromatosis. ${ }^{3}$

In the families exhibiting the SBLA (sarcoma, breast and brain tumours, leukaemia, laryngeal and lung cancer, and adrenal cortical carcinoma) syndrome, ${ }^{+7}$ melanoma was not a feature. There have, however, been occasional reports of malignant melanoma occurring as a second primary tumour in children who have had malignancies related to this syndrome, or in their close relatives: amelanotic melanoma of the cheek has developed after adrenal cortical carcinoma ${ }^{8}$ and the mother of a child with osteosarcoma herself developed a

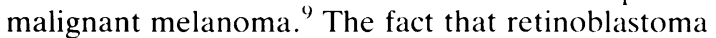
survivors are at subsequent high risk of osteosarcoma is now well recognised, but there have also been instances where malignant melanoma has been diagnosed after retinoblastoma. ${ }^{1(1-12}$

Received for publication 7 August 1986.

Revised version accepted for publication 31 October 1986.
This report is concerned with the occurrence malignant melanoma in the families of seven chil dren with osteosarcoma, chondrosarcoma, gु adrenal cortical carcinoma ascertained in the cotse of pedigree studies being carried out to det⿳亠े⿵冂⿰ overall cancer risks to close relatives of thes children.

\section{Methods}

All children aged under 15 years in the Mancheste Children's Tumour Registry (MCTR) with histologically confirmed diagnoses of osteosarcoma, chone drosarcoma, or adrenal cortical carcinoma, who were diagnosed between 1 January 1954 and 3.30 December 1983 have been included in a stud\% carried out to estimate cancer risks in close relative of these children. The MCTR is described in deta $B$ by Birch $\mathrm{et} \mathrm{al}^{1.3}$ and ascertainment of cases has bee estimated to be 95 to $98 \%$ complete. $^{1+}$

For each child included in the study the case records were abstracted with respect to the followe ing: sex, age at diagnosis, site of tumour, congenita abnormalities, and, where available, family historø of cancer.

The current general practitioners (GPs) of bothu parents of each child in the study were they identified and were asked for permission to approach the family for interview. Interviews were carried out in the parents' own homes and informaos tion was sought on past medical history, including congenital abnormalities, serious illnesses, long 
term conditions, and operations in the child anc all first degree relatives. Reports of neoplastic disease in second degree relatives and, where possible, third degree and more distant relatives were also recorded. An attempt was made to confirm reports of all neoplastic conditions in relatives by reference to hospital notes, the appropriate Regional Cancer Registry, questionnaires to GPs, or by obtaining copies of death notifications. Where possible the histology of neoplasms was reviewed.

The cumulative risk with age of malignant melanoma was estimated using population data for the North West Region. ${ }^{15}$ This was used to calculate the expected number of melanomas among the first degree relatives of the children, taking into account their age at last follow up or age at death as appropriate. Observed and expected numbers of melanomas among the relatives were compared and significance tests carried out using the method described by Rothman and Boice ${ }^{16}$ for exact testing and estimation for a Poisson variate.

\section{Results}

A total of 95 tumours occurring in 94 children was included in the study: 76 osteosarcomas, 10 chondrosarcomas, and nine adrenal cortical carcinomas. Two children were adopted and so no further information was available and one child had a double primary tumour. Hence, there were 92 families eligible for interview. A total of 64 inter- views has been obtained and a further two families have completed a postal questionnaire. Among these interviews there were seven families where reports of malignancy in relatives were confirmed as malignant melanoma. The features of melanoma in the relatives in relation to neoplastic disease in the child are shown in the table and details of the individual families are given below.

FAMILY A

Chondrosarcoma of the right humerus was diagnosed at the age of 14 years. The mother had a mole on the right thigh present from birth, which at the age of 31 started to enlarge and bleed. Wide excision was performed and the lesion was reported as a malignant malanoma.

The mother's father developed a right upper mediastinal mass at the age of 63 and died shortly afterwards. There was no biopsy or necropsy. This patient also had a number of superficial lesions on the head, possibly basal cell carcinomas, although again there was no histological confirmation. There was apparently no evidence of Gorlin's syndrome. Both the mother, her father, her sister, and the index child's two cousins had polydactyly. The mother's paternal grandfather died of lung cancer aged 75 (unconfirmed) and from family history reports must have carried the polydactyly gene. The mother's maternal grandfather's death certificate showed that he died of a brain tumour aged 60 (fig $1)$.

TABI.E: Malignant melanoma in relatives of children with osteosarcoma, chondrosarcoma, and adrenal cortical carcinoma.

\begin{tabular}{|c|c|c|c|c|c|c|c|c|c|}
\hline \multicolumn{6}{|l|}{ Relative' } & \multicolumn{4}{|l|}{ Child } \\
\hline Family & Histology & Site & $\begin{array}{l}\text { Age at } \\
\text { diag- } \\
\text { nosis } \\
\text { (y) }\end{array}$ & $\operatorname{sex}$ & $\begin{array}{l}\text { Degree of } \\
\text { relation- } \\
\text { ship }\end{array}$ & Histology & Site & $\operatorname{Sex}$ & $\begin{array}{l}\text { Age at } \\
\text { diag- } \\
\text { nosis } \\
\text { (y) }\end{array}$ \\
\hline A & $\begin{array}{l}\text { Invasive malignant } \\
\text { melanoma with adjacent } \\
\text { in situ component of } \\
\text { superficial spreading } \\
\text { type }\end{array}$ & $\mathrm{R}$ thigh & 31 & $\mathrm{~F}$ & 1 & Chondrosarcoma & $\mathrm{R}$ humerus & $\mathrm{F}$ & 14 \\
\hline B & Nodular malignant melanoma & $\mathrm{R}$ cheek & 36 & $\mathrm{~F}$ & 1 & Osteosarcoma & $\mathrm{R}$ femur & $\mathbf{M}$ & 14 \\
\hline C & $\begin{array}{l}\text { Invasive malignant } \\
\text { melanoma }\end{array}$ & $\begin{array}{l}\text { Choroid. } \\
\text { R eye }\end{array}$ & 58 & $\mathbf{M}$ & 2 & Osteosarcoma & $\mathrm{R}$ tibia & $\mathrm{F}$ & 13 \\
\hline D & Malignant melanoma & $\mathrm{R}$ forcarm & 70 & $\mathrm{~F}$ & 2 & $\begin{array}{l}\text { Adrenal cortical } \\
\text { carcinoma }\end{array}$ & $\mathrm{R}$ adrenal & $\mathrm{F}$ & 9 \\
\hline $\mathrm{r}:$ & $\begin{array}{l}\text { Invasive malignant } \\
\text { melanoma with adjacent } \\
\text { component of super- } \\
\text { ficial spreading type }\end{array}$ & $\begin{array}{l}\text { Limbal } \\
\text { conjunctiva. } \\
\mathrm{R} \text { eyc }\end{array}$ & 36 & $\mathrm{~F}$ & 2 & Osteosarcoma & $\mathrm{R}$ femur & $\mathbf{M}$ & 14 \\
\hline $\mathrm{F}$ & Malignant melanoma & Face & 32 & M & 2 & $\begin{array}{l}\text { Mesenchymal } \\
\text { chondrosarcoma }\end{array}$ & I. fibula & $\mathbf{M}$ & 2 \\
\hline ( & Malignant melanoma $\dot{x}$ & Orbit & tho & $\mathrm{F}$ & 3 & Osteosarcoma & $\mathrm{R}$ femur & $\mathrm{F}$ & 10 \\
\hline
\end{tabular}

Special pathology review. Death certificate. Clinical diagnosis. 


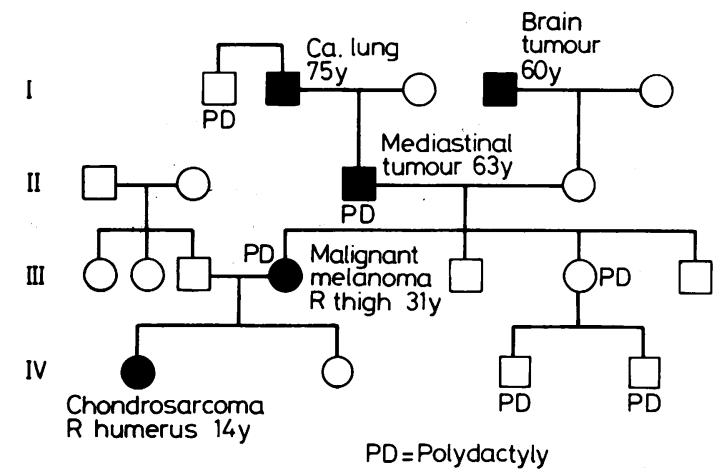

FIG 1 Pedigree of family $A$.

\section{FAMILY B}

The index patient was diagnosed as having an osteosarcoma of the right femur at the age of 14 years. His sister developed a malignant melanoma of the right cheek at the age of 36 , just above an intradermal naevus which had been present for many years. The mother of these sibs was diagnosed as having mucin producing adenocarcinoma of the stomach aged 61 and the father had a lipoma removed aged 62 .

FAMILY C

The child was diagnosed as having osteosarcoma of the left tibia aged 13 years. The father's father had his right eye enucleated at the age of 58 for a large malignant melanoma of the choroid. There is no other family history of cancer.

\section{FAM I LY D}

The child was diagnosed as having an adrenal cortical carcinoma at the age of nine years. Her maternal grandmother had died of a malignant melanoma of the right forearm aged 70 . Other family cancers included a brain tumour in the child's

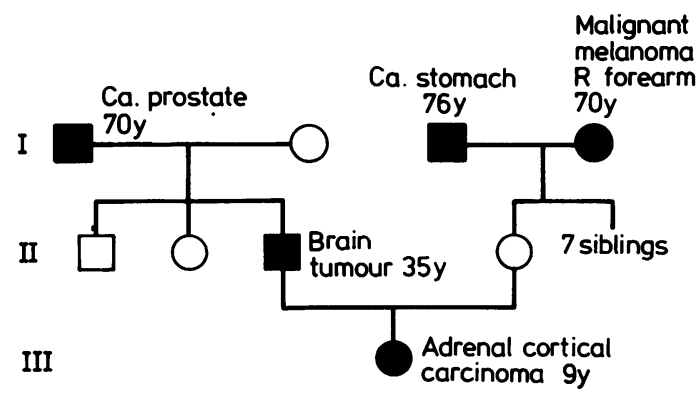

FIG 2 Pedigree of family $D$. father at the age of 35 , carcinoma of the prostate the age of 70 in the paternal grandfather, and carcinoma of the stomach at the age of 76 in the maternal grandfather (fig 2).

FAMILY E

Osteogenic sarcoma of the right femur was dia $\overline{0}$ nosed at the age of 14 years. The mother's siste्dि presented at the age of 36 with a swelling of the rigfpt eye present from birth which, after repeated ex $\vec{\Phi}$ sions, was finally reported as a malignant melanomid of the limbal conjunctiva. She is alive and well $\mathrm{g}$ years later, but has also developed multiple sebof rhoeic keratoses on the left arm, breast, and on hợ back. Other malignancies in this family include carcinoma of the lung aged 61 in the mother's father, carcinoma of the pancreas aged 63 in the mother's father's brother, and a mesentere lymphoma aged 43 in the mother's father's sisterors son. The mother herself developed severe cerebra] oedema aged 26 but there was no evidence neoplasm.

FAMILY F

The child was diagnosed as having a mesenchym $\$$ chondrosarcoma of the left fibula aged two yearse His paternal uncle presented at the age of 32 wishog pigmented, bleeding, pedunculated lesion in from the left ear which had grown over the previoussag months at the site of a freckle which had been present for some time. The lesion was clinicales diagnosed as a malignant melanoma and w\% excised. Unfortunately the specimen was mislaid $\oplus$ there was no histological confirmation of th $\vec{E}$ diagnosis. Several years later, at the age of 37 , the same patient developed a lump in the right brease Simple mastectomy was performed and the tumo proved to be papillary intraduct carcinoma. Pagets disease of the nipple was also present.

FAMILY G

The child was diagnosed as having an osteosarconf of the right femur at the age of 10 years. The dea certificate of the father's mother's mother showed that she died of malignant melanoma of the orbis aged 66. Interestingly, the father himself present at the age of 54 with a warty, pedunculated lesion the left side of the abdomen which had grown froma small mole present for about 10 years. The lesiof was strongly suspected to be a malignant melanond and wide excision was carried out. Histological examination, however, showed that the tumour wass a large pigmented basal cell papilloma with evidence of malignancy. The child's mother wess diagnosed as having infiltrating duct carcinoma of the right breast aged 51 (fig 3 ). 


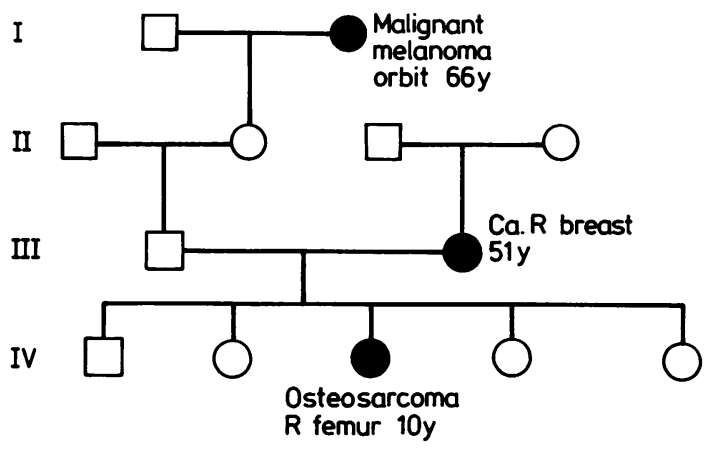

FIG 3 Pedigree of family $G$.

In one further family, the sib of a girl with an osteosarcoma was born with a black, warty, cauliflower-like lesion on the occipitoparietal region of the scalp, described as a melanoma. The mother is well but the maternal grandmother was diagnosed as having a papillomatous cystadenoma of the ovary aged 44 and died of carcinomatosis aged 57.

Information of all first degree relatives was available from the interviews and hence it was possible to estimate the relative risk to these persons of developing malignant melanoma. A total of 196 female and 195 male first degree relatives was reported. No melanomas occurred in the male relatives (expected number $=0.08$ ), but there were two cases of malignant melanoma in the female relatives (expected number $=0 \cdot 15$ ). Overall this represents a significant excess (relative risk 8.7, $\mathrm{p}=0 \cdot 023$ ). While discrepancy between population based incidence data for malignant melanoma and information gained at interview is probably minimal for first degree relatives, this is less likely to be the case for second and higher degree relatives. Hence, no accurate estimation of risk for the latter is possible.

\section{Discussion}

Mothers of children with soft tissue sarcoma and osteosarcoma and chondrosarcoma have been shown to have a significant three-fold excess risk of developing breast cancer. ${ }^{17} 18$ The association between breast cancer in mothers, soft tissue sarcomas in children, and other neoplastic disease in close relatives was first described as a possible familial syndrome by $\mathrm{Li}$ and Fraumeni in $1969 .{ }^{4}$ They considered that in the four families studied in detail it was likely that there was an inherited predisposition for the development of these tumours and that the pattern of cancers seen was compatible with the transmission of an autosomal dominant gene with pleiotropic effects. It seems likely that a similar genetic susceptibility mechanism may be operating in at least some of the families where the child develops an osteosarcoma or chondrosarcoma. The occurrence of malignant melanoma in seven of such families raises two possibilities. Firstly, malignant melanoma may be an additional manifestation of the same gene defect but with a low level of penetrance. Alternatively, there may be a separate genetic mechanism leading to the development of malignant melanoma coincidentally present in these families, which is acting to enhance the effects of the major susceptibility gene leading to tumours characteristic of the SBLA syndrome.

None of these families appears to suffer from any other syndrome known to predispose to the development of cancer. The only notable congenital abnormality was the occurrence of polydactyly in family A, which appeared to be transmitted alongside the cancer susceptibility. Polydactyly has been reported in association with retinoblastoma, ${ }^{19}$ and a small accessory thumb was also present in a patient included in the MCTR who developed Hodgkin's disease at the age of nine, followed by a leiomyosarcoma of the iris aged 13 .

The occurrence of carcinoma of the breast at the early age of 37 following malignant melanoma at the age of 32 in the paternal uncle of the child with the mesenchymal chondrosarcoma (family F) is of particular interest in view of the reported association between breast cancer and malignant melanoma. ${ }^{2}$ In family $E$ the development of multiple seborrhoeic keratosis in the malignant melanoma sufferer may be an example of the Leser-Trelat sign which has been described by Lynch et $a l^{20}$ in a mother and daughter who both had carcinoma of the breast. It is possible that this condition affected the maternal grandfather in family $\mathrm{A}$.

Some evidence for the second proposed mechanism of inheritance could be put forward from families $D$ and $G$ where melanoma occurred in one branch of the family and a brain tumour and breast cancer were present in a first degree relative from another side of the family. However, the multiple associations which have so far been reported between adrenal cortical carcinoma, breast cancer, osteosarcoma, chondrosarcoma, soft tissue sarcoma, retinoblastoma, and malignant melanoma do indicate that, in certain families at least, these tumours might all be related to the same gene defect.

The association with malignant melanoma also appears to be stronger in relation to childhood adrenal cortical carcinoma, osteosarcoma, chondrosarcoma, and retinoblastoma than in relation to childhood soft tissue sarcoma. Malignant melanoma 
has not been described in families with childhood soft tissue sarcoma and has not so far been confirmed in any close relative of more than a hundred soft tissue sarcoma children in the MCTR for whom family data are available. In addition, although soft tissue sarcomas do occur after retinoblastoma, osteosarcoma is by far the commonest second neoplasm in retinoblastoma survivors. ${ }^{12}$ Hence, there are indications that the SBLA syndrome may be related to more than one gene defect leading to similar constellations of tumours in family members. In some families, childhood soft tissue sarcomas and early onset breast cancers in the mothers may be the predominant features. In other families, such as those described here, childhood bone sarcomas may have a stronger association with adrenal cortical tumour, retinoblastoma, breast cancer, and malignant melanoma. These differences in the families may, however, be explained by different degrees of penetrance of the same gene in different genetic backgrounds or by a greater degree of genetic heretogeneity which may exist in families with soft tissue sarcomas.

We should like to thank Ewa Dale and Cora Christmas who traced the parents of the children in this study. We are grateful for the help given by general practitioners, the staff of the National Health Service Central Register, Southport, and the Family Practitioner Committees. We should also like to thank the pathologists who sent us material for review. The Manchester Children's Tumour Registry is supported by the Cancer Research Campaign.

\section{References}

1 Cawley EP. Genetic aspects of malignant melanoma. $A M A$ Arch Dermatol Syphilol 1952;65:440-50.

2 Lynch HT, Frichot BC, Lynch P, Lynch J, Guirgis HA. Family studies of malignant melanoma and associated cancer. Surg Gynecol Obstet 1975;141:517-22.

3 Gartner S. Malignant melanoma of the choroid and von Recklinhausen's disease. Am J Ophthalmol 1940:23:73-8.
+ Li FP. Fraumeni JF Jr. Soft tissue sarcomas, breast cancer an other ncoplasms. A familial syndrome? Ann Intern Met 1969:71:747-52.

5 Li FP. Fraumeni JF Jr. Prospective study of a family cancer syndrome. JAMA 1982:247:2692-4.

' Lynch HT. Mulcahy GM. Harris RE. Guirgis HA. Lynch JE Genetic and pathologic findings in a kindred with heredita sarcoma, breast cancer, brain tumours. leukemia, lunge laryngeal. and adrenal cortical carcinoma. Cancer 1978:41:205 64.

7 Lynch HT, Katz DA, Bogard PJ, Lynch JF. The sarcomê?. breast cancer. lung cancer, and adrenocortical carcinond syndrome revisited. Am J Dis Child 1985:139:134-6.

${ }^{8}$ Dargeon HW. Tumors of childhood. New York: Paul $\overrightarrow{\mathrm{B}}$ Hoeber, 1960:391.

"Glass AG. Fraumeni JF Jr. Epidemiology of bone cancer children. J Natl Cancer Inst 1970;44:187-99.

10 Tefft M, Vawter GF, Mitus A. Second primary neoplasms children. AJR 1968;103:800-22.

$"$ Meadows AT, Baum E, Fossati-Bellani F, et al. Second malignant neoplasms in children: an update from the late effects study group. J Clin Oncol 1985;3:532-8.

12 Draper GJ. Sanders BM. Kingston JE. Second primary ned plasms in patients with retinoblastoma. $\mathrm{Br} J$ Canc? 1986:53:661-71.

13 Birch JM, Marsden HB, Swindell R. Incidence of malignant discase in childhood: a 24-year review of the Manchester Children's Tumour Registry data. Br J Cancer 1980;42:215-2\$

${ }^{14}$ Leck I. Birch JM, Marsden HB, Steward JK. Methods classifying and ascertaining children's tumours. Br J Canc

15 North Western Regional Health Authority. Regional Cancy Registry. Cancer in the north west:statistics for 1975-78, ¿880

16 Rothman KJ, Boice JD Jr. Epidemiologic analysis we programmable calculator. Boston: Epidemiology Resources. 1982.

17 Birch JM, Hartley AL. Marsden HB, Harris M, Swindelf Excess risk of breast cancer in the mothers of children with sक्ठी tissuc sarcomas. Br J Cancer 1984:49:325-31.

18 Hartley AL, Birch JM, Marsden HB, Harris M. Breast cancor risk in mothers of children with osteosarcoma and chondrosa coma. Br J Cancer 1986;54:819-23.

19 Jensen OA. Retinoblastoma in Denmark (1943-1958). clinical, histopathological, and prognostic study. Acta Ophtha mol 1965:43:821-40.

20) Lynch HT. Fusaro RM. Pester JA, Lynch JF. Leser-Trelat sigh in mother and daughter with breast cancer. J Med Gent 1982:19:218-21.

Correspondence and requests for reprints to Dr A Hartley, Department of Epidemiology and Social Oncology, Children's Tumour Registry, Christ Hospital and Holt Radium Institute, Manchester M20 9BX. 